\title{
Detección y genotipificación del virus del papiloma humano de alto riesgo mediante PCR multiplex en tiempo real (RT-PCR VPH AR)
}

\section{High risk human papillomavirus detection and genotyping by multiplex real time PCR (RT-PCR HR HPV)}

\author{
Jairo A. Mesa-Arango1, Laura Joanna Tapia-Vela², \\ Natalia Loaiza-Díaz ${ }^{3}$, Julián Echeverry-Chica ${ }^{4}$, Ana Isabel Toro-Montoya ${ }^{5}$
}

\section{Utilidad clínica de la prueba}

La relación causal entre el desarrollo de cáncer de cérvix y la infección con genotipos de alto riesgo (AR) del virus del papiloma humano (VPH), ha llevado al desarrollo de estrategias para su detección y caracterización genotípica, como una medida de prevención de este tipo de cáncer. Dado que la presencia del VPH no puede ser determinada mediante los hallazgos clínicos de la paciente, como tampoco en los hallazgos morfológicos en la citología ni en la detección de anticuerpos específicos contra el VPH (pruebas serológicas), su detección y genotipificación recaen en el uso de pruebas moleculares, las cuales en su mayoría están dirigidas a la detección del ADN de los genotipos de alto riesgo, usando la técnica de reacción en cadena de la polimerasa (PCR) convencional y en tiempo real (RT-PCR) [1]. La técnica de PCR permite la amplificación de regiones específicas del ADN del VPH en los genes L1, E6 y E7, los cuales, por sus variaciones en la secuencia, permiten la genotipificación del virus [2,3].

Las pruebas de detección de ADN y/o genotipificación del VPH son consideradas herramientas de tamización en cáncer de cérvix, que detectan la infección causada por VPH. Su aplicación está enfocada en la clasificación de anormalidades citológicas,

\footnotetext{
${ }^{1}$ Microbiólogo y Bioanalista, PhD en Biología. Profesor de Cátedra, Escuela de Microbiología, Universidad de Antioquia. Coordinador Laboratorio de Biología Molecular, Laboratorio Clínico Hematológico. Medellín, Colombia. E-mail: jmesa@ hematologico.com.

${ }^{2}$ Médica, Especialista en Patología. Jefe de Patología Anatómica, Laboratorio Clínico Hematológico. Medellín, Colombia.

${ }^{3}$ Médica, Especialista en Microbiología. Jefe de Patología Clínica, Laboratorio Clínico Hematológico. Medellín, Colombia.

${ }^{4}$ Microbiólogo y Bioanalista, MSc en Microbiología y Bioanálisis, Universidad de Antioquia. Microbiólogo, Laboratorio Clíni-

co Hematológico. Medellín. Colombia.

${ }^{5}$ Bacterióloga y Laboratorista Clínica. MSc en Virología. Directora Científica, Editora Médica Colombiana S.A. Medellín,

Colombia.
} 
monitoreo de infecciones persistentes, seguimiento postratamiento de lesiones intraepiteliales de alto grado y vigilancia epidemiológica en salud pública [4-6]. La utilización de la citología y las pruebas de detección de ADN del VPH, aumenta la sensibilidad de la tamización para la detección de cáncer de cérvix y reduce de manera significativa el riesgo de sufrir lesiones cervicales premalignas por un periodo de 5 años [2,7].

\section{Fundamento de la técnica}

La RT-PCR VPH AR es una prueba de PCR multiplex en tiempo real (RT-PCR), que permite la detección cualitativa (positiva o negativa) y simultánea de 14 genotipos del VPH clasificados como de alto riesgo para cáncer de cérvix (genotipos 16, 18, 31, 33, 35, 39, 45, 51, $52,56,58,59,66$, y 68). Se basa en la amplificación de una región específica del gen L1 (gen tardío codificante para proteínas estructurales que conforman la nucleocápside viral del VPH), utilizando oligonucleótidos que detectan el ADN viral y sondas específicas que permiten de manera simultánea su diferenciación por genotipos específicos de alto riesgo $[8,9]$.

\section{Muestra y almacenamiento}

La muestra estandarizada y de elección para la detección de genotipos de alto riesgo del VPH es la que se utiliza para la citología cervicouterina en base líquida, preservada en medio ThinPrep o SurePath. Estas muestras deben ser transportadas y almacenadas en refrigeración $\left(2^{\circ} \mathrm{C}\right.$ a $\left.8^{\circ} \mathrm{C}\right)$, con el fin de garantizar una estabilidad máxima de 2 semanas. Los hisopados de cérvix también se pueden utilizar, siempre y cuando se garantice su almacenamiento en el medio de trasporte adecuado.

\section{Procedimiento}

La RT-PCR VPH AR se lleva a cabo en tres pasos: 1) extracción, análisis espectral y cuantificación del material genético (ADN viral) purificado a partir del sedimento celular obtenido de la muestra; 2) preparación de la mezcla de componentes de la reacción de RTPCR y las muestras de ADN; y, 3) amplificación del ADN viral por RT-PCR, con el análisis e interpretación de los resultados. La extracción del ADN se realiza a partir de $1.000 \mathrm{uL}$ de la muestra para citología en base líquida, los cuales son centrifugados para obtener el sedimento celular del epitelio cervical. El sedimento colectado es sometido a digestión usando detergentes, proteinasa $\mathrm{K}$ e incubación a temperaturas entre $56^{\circ} \mathrm{C}$ y $70^{\circ} \mathrm{C}$, hasta la obtención del ADN en solución acuosa, el cual es posteriormente purificado por cromatografía de adsorción en sílice. El procedimiento de extracción se realiza con el kit Qiamp DNA Mini kit (Qiagen, Alemania), siguiendo las recomendaciones del fabricante. La calidad del ADN purificado se evalúa mediante análisis espectral (relación de absorción A260 $\mathrm{nm} / \mathrm{A} 280 \mathrm{~nm}$ y A260 nm/A230 nm), y su cuantificación por absorción de luz a $260 \mathrm{~nm}$ (NanoDrop ONE-W, Thermo Fisher Scientific). El ADN purificado es posteriormente utilizado como muestra para la RT-PCR. Cada reacción corresponde a una mezcla de reactivos para la amplificación de una región específica del gen L1 del VPH, e incluye los oligonucleótidos y sondas marcadas con fluoróforos (específicas para cada genotipo), las enzimas ADN polimerasa y uracil-ADN glicosilasa, y un tampón amortiguador con los nucleótidos trifosfato (dNTPs). La amplificación del gen L1 se lleva a cabo usando un termociclador (CFX96, Bio-Rad) y los productos amplificados son detectados en tiempo real mediante la medi- 
ción de la fluorescencia emitida por los fluoróforos de las sondas, en un análisis de curvas de melting cíclico. La RTPCR tarda en promedio unas 4 horas, e incluye el corrido de tres controles positivos (mezclas de ADN sintético de los genotipos del VPH de AR detectados en la prueba: PC1, PC2 y PC3), un control negativo ( $\sin A D N)$, y un control interno (IC: gen humano de expresión constitutiva).

\section{Interpretación de los resultados}

Al finalizar la amplificación de las muestras y controles de la RT-PCR, los resultados de detección y análisis de curvas de melting cíclico son exporta- dos a un analizador automatizado que permite su interpretación y reporte. La interpretación de los resultados involucra el análisis de curvas de melting, que indican la amplificación del ADN del control interno (para cada una de las reacciones) y la amplificación del ADN del VPH (para las reacciones de los controles positivos y negativos, y las muestras de los pacientes). La amplificación del ADN en los controles, permite validar los resultados de la prueba de RT-PCR y la detección de los genotipos específicos del VPH (tabla 1). Finalmente, los datos generados en el termociclador son sometidos al análisis e interpretación automatizada, utilizando el software y los parámetros específicos que permiten su respectivo reporte.

\begin{tabular}{|c|c|c|}
\hline $\begin{array}{l}\text { Resultado obtenido en } \\
\text { la RT-PCR VPH }\end{array}$ & $\begin{array}{l}\text { Resultado del control } \\
\text { interno (IC) * }\end{array}$ & Interpretación \\
\hline,$+++0+++$ & $++\mathrm{o}+++$ & $\begin{array}{l}\text { 1. Se detectó ADN del VPH } \\
\text { 2. Se identificaron genotipos del VPH de alto } \\
\text { riesgo }\end{array}$ \\
\hline,$+++0+++$ & $+0-$ & $\begin{array}{l}\text { 1. Se detectó ADN del VPH } \\
\text { 2. Se identificaron genotipos del VPH de alto } \\
\text { riesgo } \\
\text { 3. Pueden estar presentes otros genotipos de } \\
\text { VPH adicionales que no se detectaron en la } \\
\text { muestra }\end{array}$ \\
\hline- & $++\mathrm{o}+++$ & $\begin{array}{l}\text { 1. No se detectó ADN del VPH en la muestra. } \\
\text { Prueba negativa para VPH de AR }\end{array}$ \\
\hline- & $+0-$ & $\begin{array}{l}\text { 1. Prueba de RT-PCR no válida } \\
\text { 2. El hecho de que la señal del IC sea } \\
\text { débil o negativa, indica que el proceso de } \\
\text { recolección de la muestra o la ejecución } \\
\text { de la RT-PCR fue inadecuada o presenta } \\
\text { fallas. Además, podría indicar la presencia } \\
\text { de inhibidores de la reacción en la muestra } \\
\text { procesada } \\
\text { 3. Se debe repetir la prueba de RT-PCR desde } \\
\text { la extracción de los ácidos nucleicos (ADN), } \\
\text { usando otra alícuota de la muestra original }\end{array}$ \\
\hline
\end{tabular}

*Si no se observa señal del control interno (IC) en la RT-PCR o ninguna otra señal de amplificación del ADN del VPH, se debe repetir la prueba o evaluar la presencia de inhibidores en la muestra procesada. También se puede considerar diluir la muestra, ya que la señal del control interno se puede reducir o estar ausente en presencia de una alta carga viral en la muestra. 


\section{Limitaciones y ventajas de la prueba}

La sensibilidad de esta prueba se ha estimado entre $96,9 \%$ y $98,5 \%$ para las lesiones intraepiteliales de alto grado en mujeres mayores de 30 años, en tanto que la especificidad ha mostrado valores de 94,1\% [10]. Los resultados de detección y genotipificación del VPH de alto riesgo pueden ser obtenidos entre 24 y 48 horas posteriores a la recolección de la muestra, siempre y cuando la muestra sea tomada y procesada bajo condiciones apropiadas y por personal debidamente entrenado.

La prueba de RT-PCR VPH AR puede ser aplicada a muestras de sedimento celular obtenidas y preservadas adecuadamente en los medios de transporte Surepath, Thinprep o eNAT. Si la muestra se encuentra preservada en otro medio de transporte diferente, se debe realizar una verificación del método que permita determinar la validez de los resultados.

El límite de detección de la prueba es de 50 copias/reacción. Un resultado negativo en la prueba de RT-PCR VPH AR no descarta una posible infección con otros genotipos del VPH no detectables por este método, o una posible infección con carga viral baja, inferior al límite de detección de la prueba.

\section{Referencias}

1. Toro-Montoya Al, Tapia-Vela LJ. Virus del papiloma humano(VPH)y cáncer.Med Lab2021;25:467 483. https://doi.org/10.36384/01232576.431.

2. Arbeláez-Vásquez $A$, Carreño $C$, CoñazosRamírez L, Castillo A. Implementación de la nueva guía práctica clínica para la detección y manejo de lesiones precancerosas de cuello uterino en mujeres de la ciudad de Cali, Colombia. Infectio 2020;24:20-26. https://doi. org/10.22354/in.v24i1.823.

3. Lagheden C, Eklund C, Lamin H, Kleppe SN, Lei J, Elfström KM, et al. Nationwide comprehensive human papillomavirus (HPV) genotyping of invasive cervical cancer. $\mathrm{Br} \mathrm{J}$ Cancer 2018;118:1377-1381. https://doi.org/10.1038/ s41416-018-0053-6.

4. Gradíssimo A, Burk RD. Molecular tests potentially improving HPV screening and genotyping for cervical cancer prevention. Expert Rev Mol Diagn 2017;17:379-391. https://doi.org/10.10 80/14737159.2017.1293525.

5. Groves IJ, Coleman N. Pathogenesis of human papillomavirus-associated mucosal disease. J Pathol 2015;235:527-538. https://doi. org/10.1002/path.4496.

6. Leal SM, Jr., Gulley ML. Current and emerging molecular tests for human papillomavirus-related neoplasia in the genomic era. J Mol Diagn 2017;19:366-377. https://doi.org/10.1016/j. jmoldx.2017.01.006.

7. Ministerio de Salud y Protección Social, Instituto Nacional de Cancerología-ESE. Guía de Práctica Clínica para la detección y manejo de lesiones precancerosas de cuello uterino. Guía No. 44. Bogotá D.C: Ministerio de Salud y Protección Social; 2014. Acceso 15 de marzo de 2021. Disponible en https://www. cancer.gov.co/Gu\%C3\%ADas-y-Protocolos/ Gu\%C3\%ADas-de-Practica-clinica/LPC-Guiaprofesionales.pdf.

8. Hesselink AT, Sahli R, Berkhof J, Snijders PJ, van der Salm ML, Agard D, et al. Clinical validation of Anyplex ${ }^{\mathrm{TM}}$ ॥ HPV HR detection according to the guidelines for HPV test requirements for cervical cancer screening. J Clin Virol 2016;76:36-39. https://doi.org/10.1016/j. jcv.2016.01.009.

9. Jung S, Lee B, Lee KN, Kim Y, Oh EJ. Clinical validation of Anyplex II HPV HR detection test for cervical cancer screening in Korea. Arch Pathol Lab Med 2016;140:276-280. https://doi. org/10.5858/arpa.2015-0117-OA.

10. Oštrbenk A, Xu L, Arbyn M, Poljak M. Clinical and analytical evaluation of the Anyplex II HPV HR detection assay within the VALGENT-3 framework. J Clin Microbiol 2018;56:e01176. https://doi.org/10.1128/jcm.01176-18. 